\title{
EFFECTS OF INTRAVENOUS DIGOXIN IN UNCONTROLLED AURICULAR FIBRILLATION
}

\author{
BY \\ JOHN HAMMOND AND WILLIAM WHITAKER \\ From the University Department of Medicine, The Royal Hospital, and the Regional Cardiovascular
Unit, The City General Hospital, Sheffield
}

Received December 22, 1955

Since William Withering in 1785 first recognized the effect of digitalis in the relief of dropsy and in slowing the heart rate, the drug has been used extensively in the treatment of congestive heart failure and its mode of action has been the subject of many studies. MacKenzie (1910) and Lewis (1919) taught that digitalis was of greatest value in cases of congestive heart failure with auricular fibrillation and considered that its therapeutic effect was due to slowing of the heart rate. MacKenzie (1918) did, however, admit that it should be used in cases of congestive heart failure with sinus rhythm. Wenckebach (1910) considered that the drug was of value in all types of heart failure.

Broadbent (1917), from clinical experience, and Sutherland (1919) thought digitalis to be of use in cases of heart failure with regular rhythm, especially when this was rapid. Christian $(1919,1922)$ and West and Pratt (1920) found a satisfactory response in cases with sinus rhythm and Luten (1924) and Marvin (1926), studying the effect of digitalis in patients with congestive heart failure and regular rhythm, concluded that the response depended largely on the underlying ætiology, and was better in patients with myocardial insufficiency than in cases with syphilitic and rheumatic heart disease. Gavey and Parkinson (1939) noted that digitalis frequently caused diuresis in patients in congestive heart failure with sinus rhythm, although the response was usually not so dramatic as with auricular fibrillation, and concluded that digitalis was indicated in congestive heart failure whatever rhythm was present.

The action of digitalis on the heart and circulation has been extensively studied in animals and human beings. Eppinger et al. (1924) showed that the cardiac output decreased in a patient with heart failure after treatment with digitalis, although there was clinical improvement. Harrison and Leonard (1926), using the direct Fick principle, found that the cardiac output fell in normal dogs after the intramuscular injection of digifolin, and Burwell et al. (1927) found the same effect in men after oral digitalis. Kininmonth (1928) found that digitalis produced variable changes in cardiac output in patients with heart disease and concluded that an increase was most likely to occur where the output was initially low. Ringer and Altshule (1929) also found that the cardiac output increased after giving digitalis to patients with congestive heart failure and auricular fibrillation, but only rarely if sinus rhythm was present. Dock and Tainter (1930) thought that the fall in cardiac output and venous pressure that occurred in normal dogs following an intravenous injection of digitalis was caused primarily by constriction of the hepatic veins so that blood was dammed back in the liver and portal system. The importance of this mechanism was refuted by Wood (1940), who showed that the liver decreased in size in patients with congestive heart failure following digitalis therapy. Stewart and Cohn (1932) and Stewart et al. (1938) found that the cardiac output was lower than normal in patients with congestive heart failure and that digitalis increased it in these patients and lowered it in normals. They noted that digitalis caused the size of the heart to decrease in both normal and abnormal patients and concluded that its action was to decrease the size of the heart and increase the extent of ventricular contraction. They found that the venous pressure fell if it was previously elevated. The effects were the same in patients with sinus rhythm as in those with auricular fibrillation.

Following the introduction of cardiac catheterization, numerous workers adopted this technique, since it provided a simple method of estimating cardiac output and recording directly blood pressures on the right 
side of the heart. Studying the effects of intravenous digoxin in patients with congestive heart failure, McMichael and Sharpey-Schafer (1944) suggested that the drug acted primarily by altering venomotor tone and that the increase in cardiac output was largely due to the fall in venous pressure. However, subsequent studies by Bayliss et al. (1950), by Wood and Paulett (1949), and by Harvey et al. (1949) failed to confirm this and showed that digoxin had a direct effect on the failing myocardium.

Goodman and Gilman (1941) thought that the disappearance of odema following digitalis therapy could be attributed to a fall in venous pressure and to improvement in renal function caused by an increase in cardiac output and the fall in renal venous pressure. More recently several observers have studied the changes in renal circulation following digitalis therapy and have attempted to relate the improved capacity to excrete salt and water to these changes. Eichna and Taube (1944) found that the diuresis following the intravenous injection of digoxin in patients with congestive heart failure was preceded by a fall in systemic venous pressure, though at times the latter fell and no diuresis ensued. Farber et al. (1951) and Davison and Gaddie (1951) also studied the effect of intravenous digoxin in patients with congestive heart failure and found that the renal plasma flow rose considerably in some cases indicating an increase in renal blood flow. The latter authors thought that this increase, which caused renal function to improve, was secondary to a rise in cardiac output. In a later study of the effect of intravenous digoxin on the systemic and renal circulation of patients suffering from congestive heart failure with uncontrolled auricular fibrillation, Eichna $e t$ al. (1951) found that the changes in renal plasma flow and glomerular filtration rate were much less consistent, smaller in absolute values, and slower in onset than changes in the cardiac output, heart rate, and venous pressure. They noted that a marked diuresis and increased excretion of sodium and chloride followed the injection of digoxin and thought that, in most patients, these were far greater than could be accounted for by changes in renal circulation and that digoxin might have a direct action on the renal tubules. This suggestion was supported by a moderate effect of digoxin in increasing sodium excretion in patients with noncardiac œdema and in non-œdematous subjects observed by Farber et al. (1951).

Since Eichna et al. (1951) and Davison and Gaddie (1951) arrived at different conclusions about the effect of intravenous digoxin on renal function in patients who were in congestive heart failure, further investigation of this effect of digitalis appeared desirable. The present study was designed to investigate the effect of intravenous digoxin on renal function in patients with uncontrolled auricular fibrillation. Two groups were studied: in one the patients had clinical evidence of congestive heart failure and in the other they had never experienced this complication.

\section{Material AND Methods}

Thirteen patients, of whom nine were women, and all suffered from uncontrolled auricular fibrillation were studied. Ten had chronic rheumatic heart disease; in six the lesion was mitral stenosis; in two mitral stenosis and incompetence, and in two mitral incompetence. Two cases had thyrotoxicosis and no cause was found for the auricular fibrillation in one. One man with mitral stenosis had also extensive osteitis deformans, and one woman with mitral stenosis subsequently died from polyarteritis nodosa. Six patients, had congestive heart failure, judged from the presence of peripheral œdema and rise of jugular venous pressure above the sternal angle in all phases of respiration, while the other patients had never experienced this complication. Nine patients had never been treated with digitalis previously; two had been off treatment for five and ten weeks respectively and two had received none of the drug for four and ten days respectively prior to investigation.

All observations were made about two hours after a meal with the subjects propped up comfortably in bed at an angle of approximately forty-five degrees. Cardiac output was calculated by the Fick principle from oxygen consumption, measured by collecting expired air in a Douglas bag, and from the differences in oxygen content of arterial blood, withdrawn from an indwelling needle in the brachial artery and mixed venous blood, withdrawn from the right atrium through a cardiac catheter previously introduced under fluoroscopic control. The hæmoglobin content of each blood sample was measured by a photoelectric colorimeter and from this the oxygen capacity was determined; the percentage oxygen-saturation was measured by a direct spectro-photometric method, and from these results, the oxygen-content of the sample was estimated. The renal plasma flow was measured by sodium-para-amino-hippuric acid clearance and glomerular filtration rate by inulin clearance, using the technical method described by Dick and Davies (1949). A priming injection of sodium-para-amino-hippuric acid and inulin was given and at the same time the patient drank $500 \mathrm{ml}$. of water. Thereafter plasma levels were maintained by a constant intravenous infusion of sodium para-amino-hippuric acid and inulin in a 5 per cent dextrose solution. The sustaining 
infusion was given at the rate of $1.5 \mathrm{ml}$. per minute. The filtration fraction, the fraction of the plasma passing through the kidney that is filtered by the glomeruli, was calculated by dividing the glomerular filtration rate by the renal plasma flow. The renal blood flow was calculated from the renal plasma flow and the hæmatocrit. The renal fraction of the cardiac output was used to express renal blood flow as a percentage of total cardiac output. The systolic and diastolic blood pressures were recorded sphygmomanometrically and the value of the arterial mean blood pressure was assumed to be equal to the diastolic blood pressure plus one-third of the pulse pressure. The systemic vascular resistance, in dynes sec. $\mathrm{cm} .^{-5}$ was calculated by dividing the product of the arterial mean blood pressure, in $\mathrm{cm} . \mathrm{Hg}$, the density of mercury, and the acceleration due to gravity, by the cardiac output in ml. per second. The renal vascular resistance was similarly estimated taking the perfusing pressure as the arterial mean blood pressure minus the renal venous pressure, which was assumed to be equal to the right atrial pressure measured by cardiac catheterization. The sodium in the urine was estimated by a flame photometer and the chloride by a silver nitrate potentiometric titration.

Observations were made during five accurately timed periods of urine collection of approximately twenty minutes each. The first two served as control periods and 1-1.5 mg. of digoxin was then given through the cardiac catheter over five minutes at the start of the third period of observation. Two further periods after this completed the procedure. Mixed venous and arterial blood samples were obtained as previously described at the mid points of each collection period and expired air was collected in a Douglas bag over two four-minute periods during the second and last periods of observation. The values given in the Table are the averages $(a)$ for the observations and estimations made in the first two control periods, and (b) for those made in the last period of observation when the full effects of the digoxin had become apparent. The arterial mean blood pressures were calculated from the average of at least six readings of systolic and diastolic blood pressures taken during each period of observation.

\section{RESULTS}

The results of the present investigations are summarized in the table and illustrated in Fig. 1 and 2. The six patients with congestive heart failure are grouped together in Section A, and the others without congestive heart failure are grouped in Section B.

Changes in the systemic circulation following digoxin. There was a reduction in heart rate within five minutes in all cases; the rate decreased rapidly during the first thirty minutes and then continued to fall more slowly (Fig. 1 and 2).

The systemic blood pressure rose in eight patients, five with heart failure and three without this complication. The systolic pressure increased more than the diastolic pressure, which usually showed little change. In the remaining five patients there was a reduction in systemic blood pressure, systolic and diastolic pressures falling within ten minutes in four, and after thirty minutes in one. The arterial mean blood pressure, calculated from the average systolic and diastolic pressures recorded before and after digoxin, showed an increase in six patients, a decrease in six, and no change in one, Case 5.

In five patients with heart failure, and in five without, there was a fall in right atrial pressure. This was greater in patients with heart failure, but in one without œdema but with an abnormally high initial venous pressure, there was a marked fall in right atrial pressure. In two patients without heart failure and in one with heart failure, who had received digitalis until four days prior to investigation, intravenous digoxin caused no fall in right atrial pressure.

The most dramatic changes in cardiac output occurred in four patients with congestive heart failure where the percentage increase in output was respectively $115,30,16$, and 69 . There was a slight increase in cardiac output in three patients without heart failure, but in all these the change was less than 14 per cent. In one patient with heart failure and in three without, digoxin caused no alteration in cardiac output. Two patients, one with and one without heart failure, showed a fall in cardiac output of 12 and 19 per cent respectively. Digoxin had no effect on the oxygen consumption and the changes in cardiac output were apparent from an alteration in the oxygen saturation of mixed venous blood.

From the changes in cardiac output and arterial mean blood pressure after the digoxin it was apparent that there had been a decrease in systemic vascular resistance in five patients with congestive 


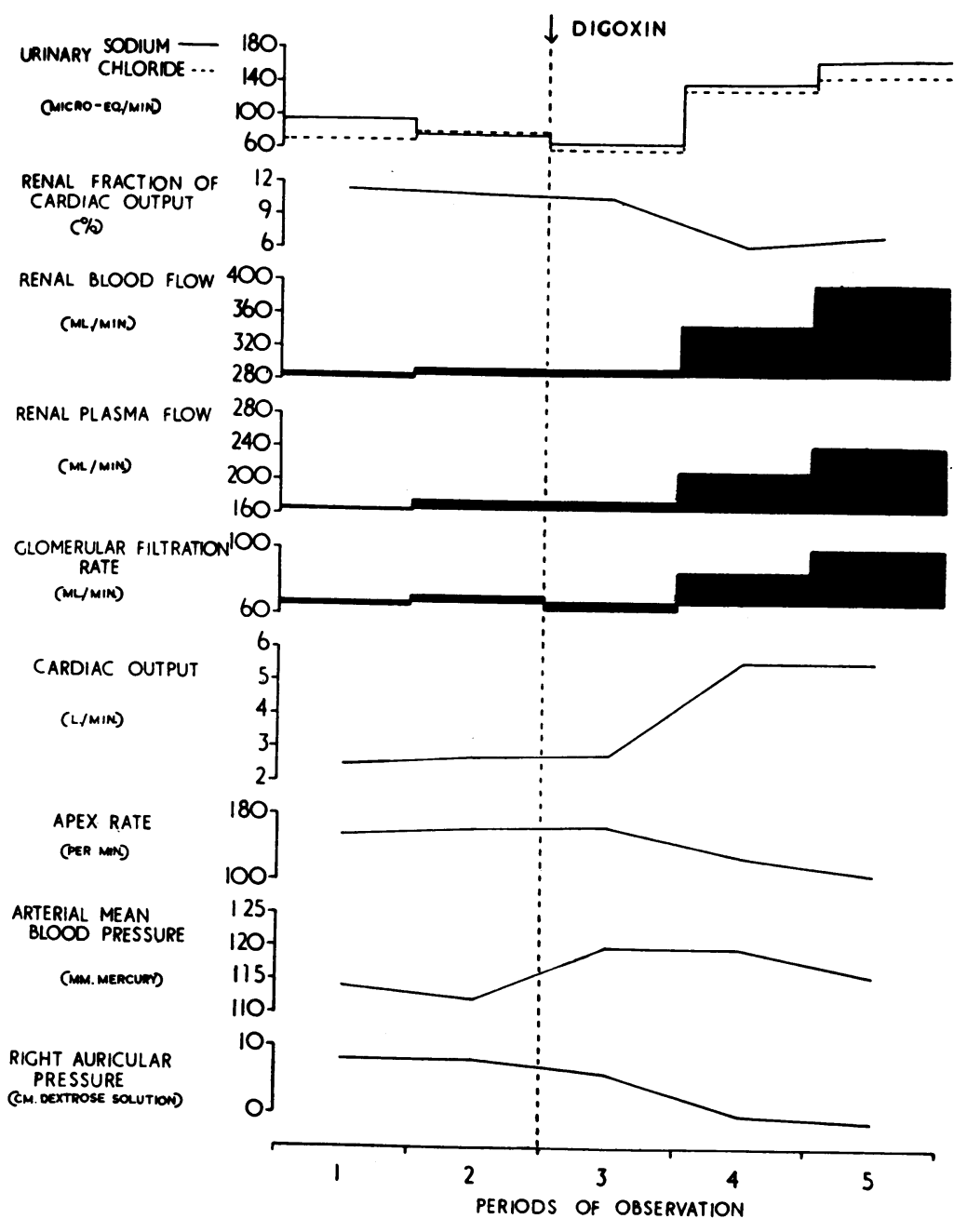

Fig. 1.-The effect of $1.0 \mathrm{mg}$. of intravenous digoxin on the systemic and renal circulations and salt excretion in Case 1.

heart failure and in three without this. In one patient with heart failure and in two without it, the systemic vascular resistance increased, and in two patients without heart failure it remained unchanged (Table).

Changes in the renal circulation following digoxin. An increase in renal blood flow, renal plasma flow, and glomerular filtration rate occurred in three patients with congestive heart failure, and an increase in renal blood flow and renal plasma flow unaccompanied by a change in glomerular filtration rate in two patients without heart failure. In the other three patients with heart failure and in the remaining patients without this, there was little or no change in renal blood flow, renal plasma flow, or glomerular filtration rate.

In one patient with heart failure and in one without it, the increase in renal plasma flow was much greater than the increase in glomerular filtration rate, which indicated a considerable decrease in the filtration fraction towards normal in these two patients. In the others the filtration fraction was little changed although it was abnormally high in seven cases. 


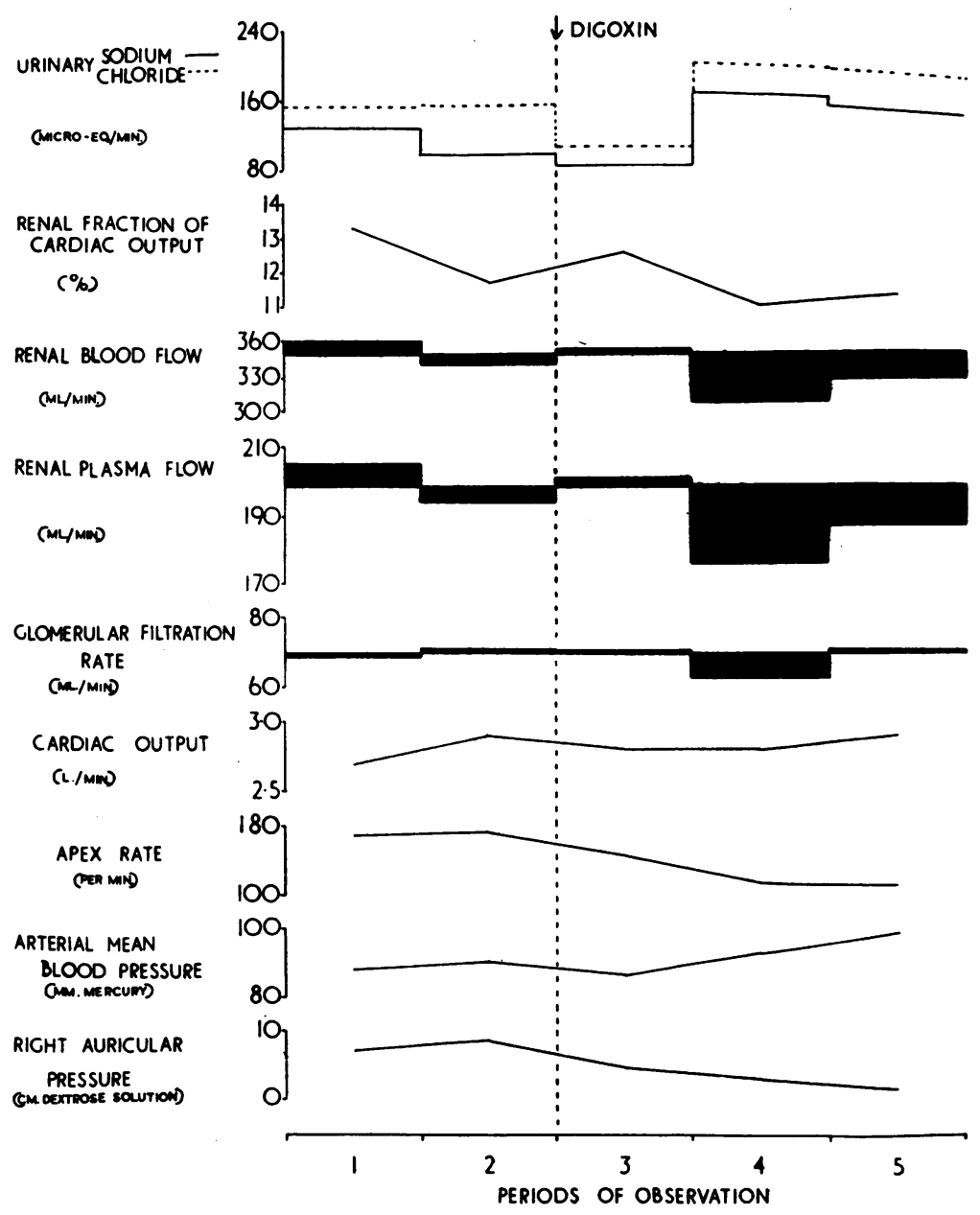

FIG. 2.-The effect of $1.5 \mathrm{mg}$. of intravenous digoxin on the systemic and renal circulations and salt excretion in Case 11.

The renal vascular resistances calculated from renal blood flow, arterial mean blood pressure, and right atrial pressure showed a fall in three patients with heart failure and in three without it. In one patient with heart failure and in two without it, there was an increase in renal vascular resistance, and in four patients, two with and two without congestive failure, little or no change.

In the patients with heart failure the renal fraction of the cardiac output, which was abnormally low in all except one, increased in one and fell or remained unaltered in the other five. In the patients without heart failure the drug was followed by an increase in the renal fraction of the cardiac output to a normal level in one, whereas in the others it remained abnormally low.

Changes in sodium and chloride excretion following digoxin. There was an increase in sodium and chloride excretion in three patients with heart failure and in six without this. In three patients the changes were small, the percentage increases being 33, 38, and 21 respectively, whereas in the other six, they were greater, the increases ranging from 57 per cent to 895 per cent. In two patients, one with and one without heart failure, there was little change in sodium and chloride excretion. In two patients with congestive failure, where the effect on chloride excretion was not studied, there was a 200 per cent increase in sodium excretion in one but no change in the other. 


\section{DisCUSSION}

Effect of intravenous digoxin upon cardiac output. In patients with clinical evidence of congestive heart failure in this series, the changes in cardiac output produced by intravenous digoxin were similar to those reported by McMichael and Sharpey-Schafer (1944), Howarth et al. (1947), Harvey et al. (1949), and Ferrer et al. (1950). Mitral stenosis was the dominant lesion in the three patients with the greatest increase in cardiac output (Fig. 1), whereas the patients showing a slight increase and no change in cardiac output after digoxin had severe mitral incompetence: it is possible that the mechanical defect of the incompetent valve prevented any increase in cardiac output. The resting cardiac output was high in the patient whose cardiac output fell after digoxin, and who had, in addition to mitral stenosis, extensive osteitis deformans. A high resting cardiac output has been described in patients with osteitis deformans by Edholm et al (1945), who also noted that this was lowered by digitalis, and by Howarth (1953).

In the patients with no clinical evidence of congestive heart failure the changes in cardiac output were in contrast to those observed in patients with congestive heart failure (Table and Fig. 2) and were more in keeping with the effects produced by digitalis in normal men (Stewart and Cohn, 1932; and Harvey et al., 1949), and in dogs (Cohn and Steele, 1932).

Effect of intravenous digoxin upon heart rate, systemic blood pressure, and right auricular pressure. The changes in heart rate, systemic blood pressure, and right atrial pressure in this series are similar to those reported by Eichna and Taube (1944), McMichael and Sharpey-Schafer (1944), Wood and Paulett (1949) and Bayliss et al. (1950).

Digoxin produced its characteristic rapid and pronounced fall in heart rate in all the patients, with and without congestive heart failure (Table and Fig. 1 and 2). Generally there was an initial rise in the systolic blood pressure and, less consistently, in the diastolic pressure. The subsequent changes were variable, but the systolic pressure usually remained raised while there was little change in the diastolic pressure.

The right atrial pressure fell in all patients with congestive heart failure with the exception of one who had received digitalis until four days before the investigation: this patient must still have been under the influence of digitalis although not sufficiently to control the heart rate. The drug produced much smaller changes in right atrial pressure in patients without congestive heart failure, and a pronounced fall was observed in only one in whom the initial level was abnormally high (Table and Fig. 1 and 2).

Effects of intravenous digoxin upon the renal circulation. Using a technique similar to the present, Davies and Kilpatrick (1951) found that in normal subjects the renal plasma flow ranged from 540 to $817 \mathrm{ml}$. per minute, the glomerular filtration rate from 119 to $183 \mathrm{ml}$. per minute, the renal blood flow from 981 to $1483 \mathrm{ml}$. per minute, the filtration fraction from $0 \cdot 18$ to $0 \cdot 30$, and that the average for the renal fraction of the cardiac output was 22 per cent. All patients in the present series before intravenous digoxin showed an abnormally low renal plasma flow, the lowest values occurring in patients with congestive heart failure (Table). One patient without heart failure had a normal glomerular filtration rate initially, but all the others had low values. The reduction in renal plasma flow was greater than that in glomerular filtration rate and most patients had abnormally high filtration fractions. An abnormally low filtration fraction in a patient with congestive heart failure is an exceptional finding and in Case 3 was probably the result of renal involvement by polyarteritis nodosa. Unusually high figures for filtration fractions, such as occurred in Cases 4 and 5, have previously been reported by Davies and Kilpatrick (1951) in patients with congestive heart failure. After intravenous digoxin there was a large increase in renal plasma flow in three patients with heart failure and in two without this. This ranged from 20 to 115 per cent. In none of the remaining patients, where the change was always less than 11 per cent, was this considered significant (Fig. 2). The effects on renal plasma flow are similar to those observed by Farber et al. (1951), who found an increase in three out of ten patients with congestive heart failure, and Davison and Gaddie (1951), who noted an increase in four out of seven similar patients after giving 
INTRAVENOUS DIGOXIN IN AURICULAR FIBRILLATION

('ulu/:ba 'o.ı!mu)

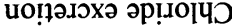

('ulu/'bə 'oдगाu)

uọฺə.ıхว un!pos

(c_-'uo 'oas saukp)

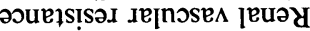

(c-'uo ·os saukp)

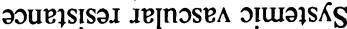

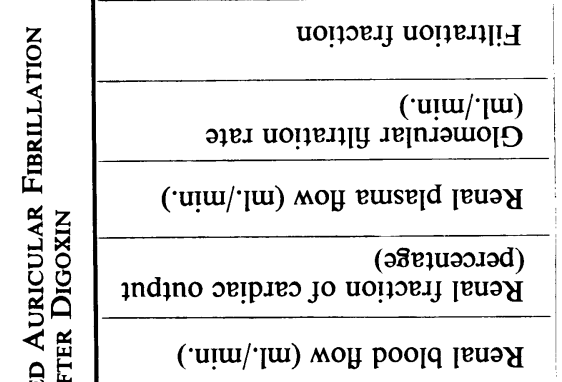

(uolunjos әsoulxəp

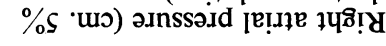

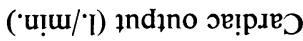

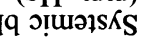

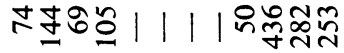

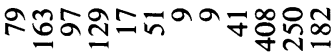

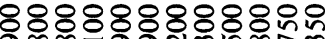

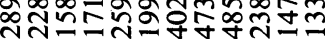

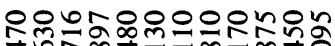

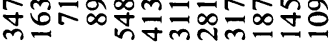

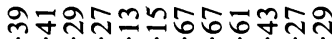
000000000000

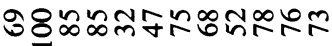

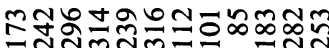

-ONamo-trmog

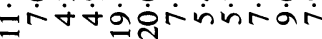

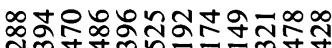

(1)

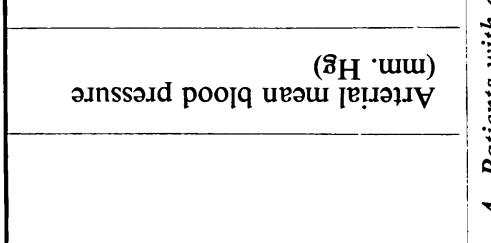

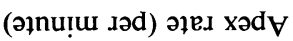

ร!souชిe!

XəS pue (S.ЕәK) วฮิ

Jəqunu əseว bomaogrnotmo

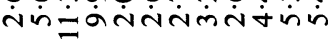

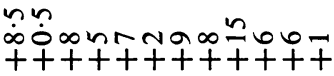

응ㅇㅇㅇㅇㅇㅇㅇㅇㅇㅇㅇㅇ

n

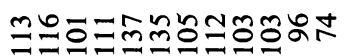

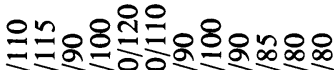

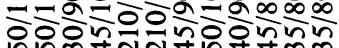

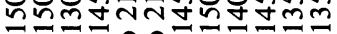

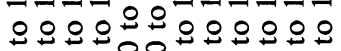

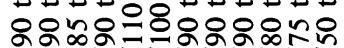

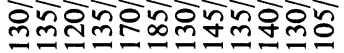

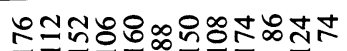

옹ㅇㅇㅇㅇㅇㅇㅇㅇㅇㅇㅇ

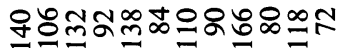

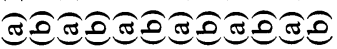

\begin{tabular}{|c|c|c|c|c|c|}
\hline$\dot{\Sigma}$ & $\sum_{*}^{\dot{\infty}}$ & $\sum_{*}^{\infty}$ & $\dot{\Sigma}$ & $\dot{\sum}$ & $\stackrel{\text { ¿ }}{\dot{\Sigma}}$ \\
\hline 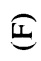 & $\sum$ & 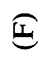 & $\sum$ & 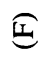 & $\overparen{E}$ \\
\hline$\stackrel{\forall}{n}$ & 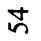 & $\tilde{n}$ & $\stackrel{\sim}{\forall}$ & $\stackrel{\infty}{m}$ & lo \\
\hline
\end{tabular}

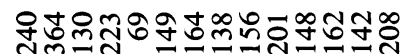

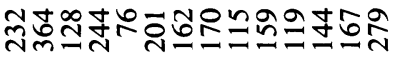

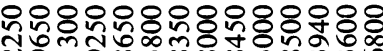

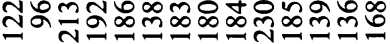

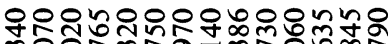

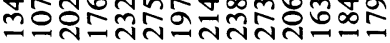

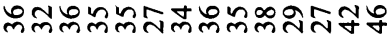
00000000000000

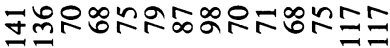

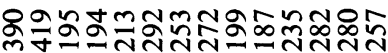

$m-\forall N \infty$ on

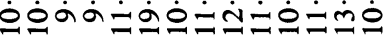

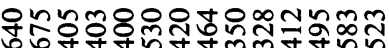

NTMt to $0000 \infty \mathrm{mma}$

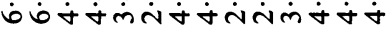

$\because n$

m-1

오옹ㅇㅇㅇㅇㅇㅇㅇㅇㅇㅇㅇㅇㅇ은

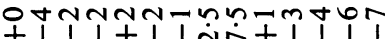
$1+$

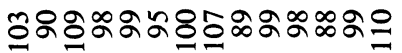

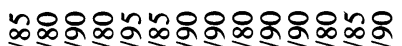

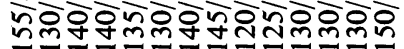

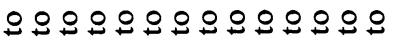

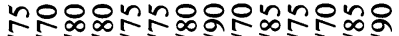

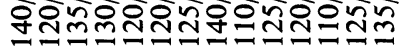

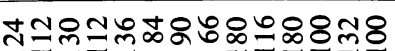

응ㅇㅇㅇㅇㅇㅇㅇㅇㅇㅇㅇㅇㅇㅇㅇㅇㅇㅇ

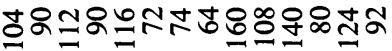

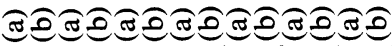

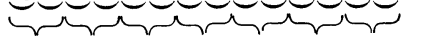

$\dot{\Sigma}$ * $\dot{\Sigma} \dot{\Sigma} \dot{\Sigma} \dot{\Sigma} \dot{\Sigma} \dot{\Sigma}^{\dot{\Sigma}}$ * *

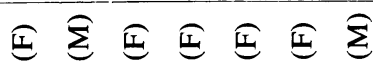

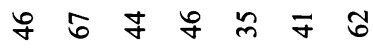


intravenous digoxin. Since renal plasma flow is directly related to renal blood flow, the present results indicate that intravenous digoxin sometimes increases renal blood flow when given to patients with uncontrolled auricular fibrillation, with or without congestive heart failure.

An abnormally high renal venous pressure has been considered as a possible factor responsible for a low renal blood flow in patients with congestive heart failure and the fall in systemic venous pressure as a cause for the increase in renal blood flow following intravenous digoxin. There is, however, little support for the view that a high renal venous pressure is the primary cause of an abnormally low renal blood flow in patients with congestive heart failure. Merrill (1946) failed to find any correlation between the depression of renal function and the height of the systemic venous or right atrial pressure in patients with congestive heart failure. Blake et al. (1949) noted that elevation of the renal venous pressure above $35 \mathrm{~cm}$. of saline reduced both renal plasma flow and glomerular filtration rate in dogs, but observed no effect from lower pressures, comparable to those usually present in patients with congestive heart failure. Seymour et al. (1942) considered that the reduction in renal blood flow in patients with congestive heart failure was proportional to the fall in cardiac output, but thought that a high renal venous pressure produced an abnormally high glomerular capillary pressure and increased the filtration fraction. Davison and Gaddie (1951) studied the effect on renal function of lowering the systemic venous pressure by venous occlusion of the thighs in patients with congestive heart failure, and found that reduction of systemic venous pressure produced no effect on renal plasma flow or glomerular filtration rate. The right atrial pressure fell in five patients with congestive heart failure in this series, but the renal blood flow increased in only three of these, where there was also a large increase in cardiac output (Fig. 1) and remained unaltered in the other two where the cardiac output did not rise. In those without heart failure the right atrial pressure fell in five, but the renal blood flow increased in only two and did not rise in the patient with the most dramatic fall in right atrial pressure (Fig. 2). These findings support those of Merrill (1946) and Davison and Gaddie (1951) and show that abnormalities in renal function in patients with congestive heart failure are not directly related to elevation of renal venous pressure. In Case 5, however, where the right atrial pressure was initially much higher than in any of the others and where intravenous digoxin caused an increase in renal blood flow out of proportion to the increase in cardiac output, it is possible that renal venous pressure was having a direct effect on renal blood flow.

All three patients with congestive heart failure who showed an increase in cardiac output, which was accompanied by an increase in renal blood flow and renal plasma flow, also had a marked increase in glomerular filtration rate following intravenous digoxin (Fig. 1). In two of these, the increase in glomerular filtration rate was proportional to that in renal plasma flow and there was little change in filtration fraction. In the other, where the renal plasma flow increased relatively more than the glomerular filtration rate and the filtration fraction fell, the extremely high renal venous pressure before treatment may have been making an active contribution to glomerular filtration as suggested by Seymour et al. (1942). Intravenous digoxin caused no significant change in glomerular filtration rate in any of the other patients (Fig. 2) and there was little change in filtration fraction except in Case 9, where an increase in renal blood flow was associated with a much smaller increase in glomerular filtration rate.

These results indicated that the changes in renal blood flow, which followed the administration of intravenous digoxin to patients with uncontrolled auricular fibrillation and congestive failure, closely paralleled the changes in cardiac output and were not directly related to lowering of the renal venous pressure. The changes in renal blood flow were reflected in similar changes in renal plasma flow and glomerular filtration rate. In patients with uncontrolled auricular fibrillation without congestive failure intravenous digoxin occasionally produced an increase in renal blood flow unaccompanied by a similar change in glomerular filtration rate.

Effect of intravenous digoxin upon systemic and renal vascular resistances and the renal fraction of the cardiac output. In the patients with congestive failure the systemic vascular resistance fell in five and in four of these the renal vascular resistance also fell. In one in whom the initial right 
atrial pressure was very high, the renal vascular resistance fell proportionately more than the systemic vascular resistance and the renal fraction of the cardiac output increased. In Cases 1 and 6 the fall in systemic was proportionately greater than that in renal vascular resistance and the renal fraction of the cardiac output decreased. In Case 3 the systemic and renal vascular resistances were similarly affected and there was no change in the renal fraction of the cardiac output. Although the systemic vascular resistance fell in Case 4, the renal vascular resistance rose and the renal fraction of the cardiac output was less after intravenous digoxin. Both systemic and renal vascular resistances increased in Case 2 and there was a slight fall in the renal fraction of the cardiac output. These findings are similar to those of Eichna et al. (1951) and show that, in most patients with uncontrolled auricular fibrillation and congestive heart failure, intravenous digoxin causes a fall in total peripheral vascular resistance which affects the renal vascular resistance less than that elsewhere. The fall in total peripheral resistance is probably a reflex baroceptor response since Ead et al. (1952) and Sharpey-Schafer (1953) showed that an increase in pulse pressure, such as follows intravenous digoxin, causes peripheral vasodilatation.

In the patients without congestive heart failure, the systemic and renal vascular resistances decreased proportionately in three, and the renal fraction of the cardiac output was unaltered. In one there was no significant change in either vascular resistance; in one the systemic and renal vascular resistance increased and in both of these patients the renal fraction of the cardiac output was unaltered. In Case 13 the systemic vascular resistance remained the same but the renal vascular resistance increased and the renal fraction of the cardiac output fell. In Case 9 there was a large increase in the renal fraction of the cardiac output after digoxin, since the renal vascular resistance fell while the systemic vascular resistance rose. These results show that the effects of intravenous digoxin upon peripheral vascular resistance are less consistent in patients with uncontrolled auricular fibrillation without heart failure than in similar patients with heart failure, and suggest that digitalis has no direct effect on the peripheral circulation and no immediate action in restoring a normal distribution of blood to the kidneys.

Effect of intravenous digoxin upon sodium and chloride excretion. There was a marked increase in salt excretion in three patients with and in four without congestive heart failure. A slight but smaller increase also occurred in one with and in two without heart failure. The patients with heart failure in whom there was a marked increase in salt excretion were the only ones showing a significant rise in cardiac output, renal blood flow, renal plasma flow, and glomerular filtration rate, and the enhanced excretion was probably due to the larger tubular load (Fig. 1). The increase in tubular load would also be more than sufficient to produce the changes seen in Cases 9, 11, and 12 (Fig. 2), but in Cases 2, 7, 8, and 13 no alteration in tubular load was apparent to account for the rise in salt excretion. In one this was within the limits of physiological variation demonstrated by Stanbury and Thomson (1951) in normal subjects, but in the other three where the increases in salt excretion were greater, digoxin may have directly depressed tubular reabsorption of salt, although the enhanced excretion could have been produced entirely by a change in tubular load too small to be apparent from the method of estimating glomerular filtration rate. Farber et al. (1951), and Eichna et al. (1951) also thought that digoxin directly affected salt excretion by decreasing tubular reabsorption.

All the patients in the present investigation were given $500 \mathrm{ml}$. of water to ensure adequate urine flows and it was impossible to assess accurately the diuretic effect of intravenous digoxin, because of the possibility of an associated water diuresis. However, in all the patients in whom there was much increase in salt excretion, there was also a sustained water diuresis.

\section{SUMMARY}

Changes in systemic and renal circulations and salt excretion following a single intravenous injection of digoxin were studied in thirteen patients with uncontrolled auricular fibrillation, of whom six had congestive heart failure. 
The heart rate decreased in all thirteen patients. The cardiac output increased in four patients with congestive heart failure, was unchanged in one, and decreased in the other. Much smaller changes occurred in those without heart failure.

In most patients there was an initial rise in systolic blood pressure and, less consistently, in diastolic pressure. The subsequent changes were variable, but the systolic pressure usually remained raised while there was little change in the diastolic pressure.

In five patients with heart failure the right atrial pressure decreased and in the other it remained unchanged. Only one patient without heart failure showed much fall in right atrial pressure and she had an unusually high initial level.

Before digoxin all thirteen patients had abnormally low renal blood flows and renal plasma flows and all but one patient, without heart failure, had low glomerular filtration rates. The smallest values were seen in those with heart failure. After digoxin there was an increase in renal blood flow, renal plasma flow, and glomerular filtration rate in three of four patients with heart failure who showed an increase in cardiac output. In two without heart failure there was an increase in renal blood flow and renal plasma flow which was independent of an increase in cardiac output and was unaccompanied by a similar change in glomerular filtration rate. In the other eight there was little or no change in renal circulation.

In most patients changes in renal plasma flow and glomerular filtration rate were unaccompanied by alterations in filtration fractions, which remained abnormally high.

The systemic vascular resistance fell in all except one patient with congestive heart failure, but no consistent changes occurred in those without heart failure. Digoxin did not appear to have any direct effect on peripheral vascular resistance since the changes observed in those with heart failure were probably due to a reflex baroceptor response. There were no uniform changes in the renal vascular resistance.

Although the renal fraction of the cardiac output was initially abnormally low in most patients, digoxin produced no consistent change in this fraction, and appeared to have no immediate effect in restoring a normal distribution of blood to the kidneys.

There was a large increase in salt excretion in all three patients with congestive heart failure who showed a rise in cardiac output, renal blood flow, renal plasma flow, and glomerular filtration rate. This increase in salt excretion was probably caused by an improvement in renal circulation following the rise in cardiac output. There was, however, an increase in salt excretion in some others where there was no evidence of a change in the tubular load, suggesting that digoxin also had a direct effect on tubular reabsorption of salt.

We wish to thank Dr. J. W. Brown and Professor C. H. Stuart-Harris for allowing us to investigate patients under their care, and Mr. A. F. Nicholls, Miss S. Exley and Miss M. S. Greaves, B.Sc., for technical assistance.

\section{REFERENCES}

Bayliss, R. I. S., Etheridge, M. J., Hyman, A. L., Kelly, H. G., McMichael, J., and Reid, E. A. S. (1950). Brit. Heart J., $12,317$.

Blake, W. D., Wégria, R., Keating, R. P., and Ward, H. P. (1949). Amer. J. Physiol., $157,1$.

Broadbent, Sir J. (1917). Lancet, 1, 965.

Burwell, C. S., Neighbours, D. W., and Regen, E. M. (1927). J. Clin. Invest., 5, 125.

Christian, H. A. (1919). Amer. J. med. Sci., 157, 593.

(1922). Medical Clinics of North America, 5, 1173.

Cohn, A. E., and Steele, J. M. (1932). J. Clin. Invest., 11, 871.

Davies, C. E., and Kilpatrick, J. A. (1951). Clin. Sci., 10, 53.

Davison, P. H., and Gaddie, R. (1951). Quart. J. Med. N.S., 20, 389.

Dick, A., and Davies, C. E. (1949). J. Clin. Path., 2, 67.

Dock, W., and Tainter, M. L. (1930). J. Clin. Invest., 8, 467.

Ead, H. W., Green, J. H., and Neil, E. (1952). J. Physiol., 118, 509.

Edholm, O. G., Howarth, S., and McMichael, J. (1945). Clin. Sci., 5, 249.

Eichna, L. W., and Taube, H. (1944). Amer. Heart J., 27, 641.

-, Farber, S. J., Berger, A. R., Earle, D. P., Rader, B., Pellegrino, E., Albert, R. E., Alexander, J. D., Taube, H., and Youngwirth, S. (1951). J. Clin. Invest., 30, 1250.

Eppinger, H., von Papp, L., and Schwarz, H. (1924). Über das Asthma Cardiale. Berlin. 
Farber, S. J., Alexander, J. D., Pellegrino, E. D., and Earle, D. P. (1951). Circulation, 4, 378.

Ferrer, M. I., Harvey, R. M., Cathcart, R. T., Webster, C. A., Richards, D. W., Inr., and Cournand, A. (1950). Circulation, 1, 161.

Gavey, C. J., and Parkinson, J. (1939). Brit. Heart J., 1, 27.

Goodman, L., and Gilman, A. (1941). The Pharmacological Basis of Therapeutics. New York.

Harrison, T. R., and Leonard, B. W. (1926). J. Clin. Invest., 3, 1.

Harvey, R. M., Ferrer, M. I., Cathcart, R. T., Richards, D. W., Jnr., and Cournand, A. (1949). Amer. J. Med., 7, 439.

Howarth, S. (1953). Clin. Sci., 12, 271.

McMichael, J., and Sharpey-Schafer, E. P. (1947). Clin. Sci., 6, 187.

Kininmonth, J. G. (1928). Quart. J. Med., 21, 279.

Lewis, T. (1919). Brit. med.J., 2, 621.

Luten, D. (1924). Arch. intern Med., 33, 251.

Marvin, H. M. (1926). J. Clin. Invest., 3, 521.

McMichael, J., and Sharpey-Schafer, E. P. (1944). Quart. J. Med., N.S., 13, 123

McKenzie, J. (1910). Heart, 2, 273.

(1918). Principles of Diagnosis and Treatment in Heart Affections. Oxford Medical Publication.

Merrill, A. J. (1946). J. Clin. Invest., 25, 389.

Ringer, M., and Altschule, M. (1929). Amer. Heart J., 5, 305.

Seymour, W. B., Pritchard, W. H., Longley, L. P., and Hayman, J. M. Jnr. (1942). J. Clin. Invest., $21,229$.

Sharpey-Schafer, E. P. (1953). J. Physiol., 122, 351.

Stanbury, S. W., and Thomson, A. E. (1951). Clin. Sci., 10, 267.

Stewart, H. J., and Cohn, A. E. (1932). J. Clin. Invest., 11, 917.

, Deitrick, J. E., Crane, N. F., and Wheeler, C. H. (1938). Arch. intern. Med., 62, 569.

Sutherland, G. A. (1919). Quart. J. Med., 12, 183.

Wenckebach, K. F. (1910). Brit. med. J., 2, 1600.

West, H. F., and Pratt, J. H. (1920). J. Amer. med. Ass., 75, 77.

Withering, W. (1785). An Account of the Foxglove and some of its Medical Uses. London.

Wood, P. (1940). Brit. Heart J., 2, 132.

- , and Paulett, J. (1949). Brit. Heart J., 11, 83. 